\title{
Titulo: DERECHOS HUMANOS y FORMACIÓN POLICIAL
}

Institución: NUCLEO DE ESTUDIOS SOCIOCULTURALES- ESCUELA SUPERIOR

DE TRABAJO SOCIAL

Autor: ADRIANA G. CLAVIJO

Mail: Adriana clavijo@yahoo.com

Esta ponencia se halla enmarcada en el desarrollo de la investigación "Derechos Humanos y formación policial”, como avances del Proyecto de Investigación Seguridad/Inseguridad y Violencia en la provincia de Buenos Aires. Un estudio de las representaciones sociales y de las políticas de seguridad, que se está llevando a cabo en el Núcleo de Estudios Socioculturales de la Escuela Superior de Trabajo Social, UNLP.

La misma tiene como objetivo analizar las transformaciones producidas en la formación policial de la provincia de Buenos Aires, en particular los contenidos curriculares relacionados con Derechos Humanos y las representaciones que los agentes de seguridad tienen acerca de los mismos.

La pretensión no es realizar un análisis en profundidad de todos los contenidos curriculares presentes en la formación, sino más bien señalar algunos contenidos curriculares en donde se presentan diferentes concepciones que se podrían relacionar con los derechos humanos, presentes en diferentes momentos históricos en la formación policial.

En particular en esta ponencia quisiera hacer especial hincapié en la Doctrina Social de la Iglesia y su concepción de Derechos de la persona humana presente en la formación policial durante la última dictadura militar, como subsuelo estructurante/conformador de la subjetividad policial.

Cabe hacer una aclaración con respecto al concepto de formación. Considero a los contenidos curriculares como parte del proceso de formación de la subjetividad institucional más amplio y complejo, en el que se va conformando la historia de los sujetos al interior de la institución, en relación con el proceso histórico, cultural, político y social que lo configura.

\section{INTRODUCCIÓN}

Las policías forman parte del sistema de control social en todos los estados modernos y constituyen uno de sus dispositivos disciplinarios ${ }^{1}$.

\footnotetext{
${ }^{1}$ Foucault plantea que la sociedad para mantener la criminalidad dentro de límites económicos y socialmente aceptables que garanticen el funcionamiento social organiza mecanismos legales que fijan la partición binaria de
} 
El poder de policía, si bien en su surgimiento en el Absolutismo Monárquico, estaba ligado a la idea de buen gobierno y buena administración de la cosa pública, fue incorporándose como institución al centro de la soberanía política del estado moderno. Se comprende también, como una forma de racionalidad en expansión que se fue conjugando con los diferentes poderes en el conjunto de las relaciones sociales.

Para Michel Foucault policía y gubernamentalidad son dos conceptos imbricados, encabalgados. Refiriéndose al soberano plantea que "la policía es la gubernamentalidad" directa del soberano como tal, en cierta forma fundante del poder soberano ${ }^{2}$ en el siglo XVIII. El poder policíaco actuaba sobre toda la totalidad del estado, "como cuerpo visible e invisible del monarca",

La expansión demográfica del siglo XVIII ligada a la abundancia monetaria y el aumento de la producción agrícola entre otros factores, contribuyeron al surgimiento de la población como problema del estado. Paulatinamente la población se trasforma en objeto de gobierno y de esta manera las disciplinas cobran vital importancia en cuanto manejo de población desde el detalle, y es ahí donde cobra vital importancia la policía.

Foucault plantea que el proceso de gubernamentalización del estado moderno tiene una forma de triangulo compuesto por soberanía, disciplina y gestión gubernamental “cuyo blanco principal es la población y cuyo mecanismos esenciales son los dispositivos de seguridad(...) Define entonces a la "gubernamentalidad como el conjunto constituido por las instituciones, los procedimientos, análisis y reflexiones, los cálculos y las tácticas que permiten ejercer esa forma bien especifica, aunque compleja, de poder que tiene por blanco principal la población, por forma mayor de saber la economía política y por instrumento técnico esencial los dispositivos de seguridad.(...)tendencia...que en todo occidente no dejo de conducir y desde hace mucho hacia la preeminencia de un tipo de poder que podemos llamar "gobierno" sobre todos los demás..." 4

permitido/prohibido y sus castigos. Estos mecanismos están dentro de lo que considera mecanismos legales o jurídicos. El segundo mecanismo es el disciplinario, de vigilancia y control. Después enumera las técnicas que considera adyacentes: policiales, medicas, sicológicas, que corresponden a la vigilancia, el diagnostico y la transformación de los individuos. Por ultimo el dispositivo de seguridad es un conjunto de fenómenos que van ha inserta el delito dentro de una serie de acontecimientos probables. Estos mecanismos no son sucesivos, no desaparece uno después del otro sino que se transforma. Todas las sociedades son de "soberanía", tal y como nuestro autor las describe, lo que ocurre es que la forma de su ejercicio se va transformando históricamente. En su texto Seguridad, territorio y población, en su clase del 11 de enero de 1978.

${ }^{2}$ Foucault, M., Seguridad territorio y población. Buenos Aires, editorial Fondo de Cultura Económica, 2006, Pág. 388.

${ }^{3}$ Foucault, M., Vigilar y castigar. Nacimiento de la prisión. Buenos Aires, editorial Siglo XXI, 2002. Pág. 216

${ }^{4}$ Foucault, M., Seguridad territorio y población. Buenos Aires, editorial Fondo de Cultura Económica, 2006, pág. 136 
Siguiendo a Foucault, la policía en su desarrollo histórico se ha ido constituyendo como uno de los dispositivos más importantes, como una técnica ${ }^{5}$ que forma parte del mecanismo disciplinario $^{6}$, de vigilancia y control del estado moderno.

En su accionar pone en evidencia la violencia constitutiva del derecho, que junto al aparato de justicia, permite, desde esta concepción, impedir la comisión de delitos: "Policía y justicia deben marchar juntas como las dos acciones complementarias de un mismo proceso, garantizando la policía "la acción de la sociedad sobre cada individuo" y la justicia "los derechos de los individuos contra la sociedad". 7

Este dispositivo gubernamental, el desarrollo de este poder disciplinario y sus diferentes maneras de concebirlo, hay que analizarlos en relación con el contrato social dentro del estado burgués.

En este sentido M. Raffin plantea que: “el modelo burgués es bien claro: el mecanismo fundamental de su lógica, el contrato, juego metonímico de la transacción comercial del libre mercado, provee las bases para la formación del edificio político. La polis moderna no es mas que un acuerdo entre partes libres que dan algo a cambio de otra cosa, que ceden la libertad de la que gozan en el estado de naturaleza para volverse más libres, para obtener una seguridad que no poseen..., 8

La teoría del contrato social entonces, plantea que la necesidad obliga a los hombres a ceder parte de su libertad al poder público a cambio de la seguridad de su vida y de sus bienes. Y en este sentido todo lo que ponga en riesgo dicha seguridad, el delincuente, es visto como una amenaza a todo el poder público. Quien viola el pacto se convierte en el enemigo de toda la sociedad y participa, al mismo tiempo en el castigo que se le impone. El más pequeño delito ataca toda la sociedad; y toda la sociedad - comprendido el infractor - está presente en la más pequeña sanción. El castigo penal es, pues, una función general, co-extensiva al cuerpo social. Foucault plantea que la noción de peligrosidad es parte de las teorías criminológicas de finales del siglo XIX. Es una noción que instala en determinados sujetos sociales

5 En este sentido no se refiere a la policía como una institución aislada, sino que la incluye dentro de otras técnicas como las médicas, sicológicas, que corresponden a la vigilancia, el diagnóstico y la transformación de los individuos, dentro del mecanismo disciplinario, de vigilancia y control.

6 Foucault, Michel: Vigilar y castigar. El nacimiento de la prisión. Buenos Aires, editorial Siglo XXI, 2002 pág. 218 "La disciplina no puede identificarse ni con una institución ni con un aparato. Es un tipo de poder, una modalidad para ejercerlo implicando todo un conjunto de instrumentos, de técnicas, de procedimientos, de niveles de aplicación de metas. Es una física o una anatomía del poder, una tecnología".

${ }^{7}$ Foucault, Michel., op. Cit. p. 101

${ }^{8}$ Raffin, Marcelo, La experiencia del horror. Buenos Aires, Editorial Editores del puerto, Colección Tesis Doctoral, 2006, pág. 11 
comportamientos virtualmente peligrosos, y que por lo tanto deben ser controlados. Y que ese control y vigilancia debe estar en manos de la policía.

Otro de los conceptos y relaciones fundantes de las prácticas policiales en la modernidad es la relación entre derecho y violencia, en tanto que la policía se constituye en la modernidad como la institución que detenta el "monopolio legitimo de la violencia".

Agamben ${ }^{9}$ refiriéndose a como los sujetos sociales se sujetan al poder disciplinario plantea que el problema de la sujeción voluntaria de los ciudadanos al ordenamiento democrático, esta en relación con el proceso de subjetivación, por medio del cual los sujetos se insertan en una red de relaciones de poder. Estas relaciones conforman un campo de fuerzas, una red de relaciones en la cual el sujeto esta inmerso. Dicho campo está compuesto por tensiones que se oponen: una que tiende a la subjetivación y otra a la desubjetivación ${ }^{10}$. Los procesos de desubjetivación son los procesos que podrían jugar a favor de la desactivación de las relaciones de poder, o sea contra las subjetivaciones que sostienen un determinado campo de juegos de poder vigentes.

En este sentido podría inscribirse una definición de los Derechos humanos ${ }^{11}$ como procesos que tiende a la desubjetivación y desactivación de las relaciones de poder inscriptas por el habitus ${ }^{12}$ A la conformación de un nuevo campo de relaciones de poder que exprese como plantea Herrera Flores: "el impulso a los procesos de subjetivación que han permitido a lo largo de la historia situarnos contra los desmanes de las diferentes globalizaciones del capital., 13

\footnotetext{
${ }^{9}$ Agamben, Giorgio, Estado de excepción. Homo Sacer, II,I. Buenos Aires, editorial Adriana Hidalgo, 2003. 10 Néstor Garcia Canclini, en Ideología y Cultura. Cursos y conferencias, Fac. Filosofía y Letras, U.B.A:, (1984). (Mimeo) establece una diferencia entre práctica y praxis con respecto al concepto bourdiano de habitus. El concepto de habitus tiene que ver con la práctica que repoduce el sistema social, en cambio la praxis tiene que ver con la transformación de las estructuras objetivas. En el mismo sentido Agamben hace la distinción entre subjetivación y desubjetivación.

11 El concepto de Derechos Humanos utilizado fue ampliamente desarrollado por el NES en anteriores ponencias. En las mismas se consideraba a los derechos humanos como producto de una conquista de la sociedad, son el resultado de grandes luchas sociales y políticas y en el proceso de su reconocimiento y evolución han influido distintas corrientes del pensamiento filosófico, religioso, político y jurídico. Son una invención y un dispositivo de la modernidad, que se desarrollan históricamente con la aparición de la expansión del modo de producción y de las relaciones sociales capitalistas. Aparecen en el mundo occidental y por lo tanto lleva consigo una dificultad de traducción en otros marcos culturales de interpretación.

$12 \mathrm{La}$ interiorización de las relaciones de poder o estructuras estructurantes, es lo que Bourdieu denomina como Habitus: complejo de disposiciones, de esquemas básicos de percepción, pensamiento y acción. Como un sistema de disposiciones durables y transponibles a nuevas situaciones. Es en esta estructuración de la vida cotidiana que se va arraigar la hegemonía.

13Herrera Flores, J.: Los derechos humanos en el contexto de la globalización: tres precisiones conceptuales. Ponencia presentada en el marco del Coloquio Internacional-Dereito e Justica no Século XXI- Coimbra Brasil 2003
} 


\section{RELACIÓN DE LOS DERECHOS HUMANOS CON LAS PRÁCTICAS POLICIALES}

Estamos asistiendo en estos últimos treinta años en la argentina a un despliegue en la sociedad y la cultura de lo que podríamos llamar paradigma de los derechos humanos, fuertemente asociado al impacto de la última dictadura militar. El mismo ha atravesado en forma significativa discursos y practicas que recorren todo el espectro social. Las acciones llevadas adelante por diferentes organismos de derechos humanos protagonistas por los reclamos de memoria, verdad y justicia, han construido un camino de lucha que ha formateado las maneras del quehacer político en materia de exigencias al estado.

A estos se suman desde diferentes concepciones ideológicas, organismos y organizaciones que reclaman al Estado por la muerte, tortura y desaparición de personas en democracia, ligadas en su mayoría al accionar de las fuerzas de seguridad, y que han incorporado en sus maneras de demandar, consignas, lugares y discursos de los organismos históricos de Derechos Humanos.

Por otra parte, el Estado argentino, a partir de la incorporación en su Constitución de diferentes instrumentos internacionales de Derechos Humanos, que lo ubica en un esquema internacional de promoción y protección de derechos, se ve obligado a responder por sus violaciones en el plano internacional.

Particularmente en la Provincia de Buenos Aires diferentes instituciones gubernamentales de promoción y protección de Derechos Humanos tales como la Secretaria de Derechos Humanos; la Dirección de Asistencia a la Víctima; la Comisión de la Memoria; comisiones de derechos humanos de las cámaras de diputados y senadores entre otras, intentan dar respuesta a las demandas y denuncias cada vez mayores sobre la violencia estatal y general.

Asimismo las reformas policiales dentro del marco de las políticas públicas de seguridad han sufrido avances y retrocesos, poniendo en tela de juicio dicha política de reforma.

En el transcurso de 11 años en la provincia de Buenos Aires (1994-2005), y a lo largo de tres ejercicios de gobierno (Duhalde, Ruckauf/Solá, Solá), se producen tres cambios en la política de seguridad, y consecuentemente en la Policía Bonaerense. Posterior a la intervención civil en la policía, durante los últimos meses del año 1997, se crea el Ministerio de Justicia y Seguridad, en el marco del cual harán su aparición la nueva Ley de Seguridad Pública (Ley 12154) y de Organización de las Policías de la Provincia de Buenos Aires (Ley 12155), que regirá desde agosto de 1998 en toda la provincia ${ }^{14}$.

\footnotetext{
${ }^{14}$ Con estas leyes, la autoridad máxima de la policía pasa a ser un civil con rango de Ministro, a la vez que se unifica esta área con la de Justicia, creando el Ministerio de Justicia y Seguridad, se unifica también el mapa
} 
A pesar de todos estos cambios, sumados a las acciones de los diferentes organismos de derechos humanos, y organizaciones de la comunidad enfocadas en distintas formas de promoción y protección de derechos, se ha producido un escaso impacto en relación a la magnitud de las violaciones de derechos por parte de los agentes de seguridad.

\section{LA FORMACIÓN POLICIAL: LA ESCUELA JUAN VUCETICH}

En esta etapa de la investigación estoy realizando trabajo de campo en la Escuela Vucetich en tanto representa, en materia de formación profesional un lugar emblemático. El mismo tiene como objetivo relevar información relacionada con los programas de estudios y registrar los cambios producidos en los contenidos curriculares como parte del proceso de formación, fundamentalmente en los contenidos relacionados con la formación en DDHH.

Del material obtenido en la Dirección de enseñanza de la Escuela Juan Vucetich, donde se archivan los planes de estudio dictados, he podido relevar desde el año 1969 al 1972 solo el material que figuraba en los analíticos de los cadetes registrados en los "Libros Mayores" numerados por períodos de uno o dos años. Los más viejos datan del año 1969 y están registradas las materias correspondientes a cada curso vigentes en el año con sus asignaturas correspondientes.

Los períodos de tiempo corresponden con los cursos dictados durante los años 1969/70/71/73/1974/76/80/84/85/87/89/92/99/2000/2001/2005.

De una primera lectura de los programas de diferentes asignaturas en las que se mencionan contenidos relacionados: concepto de hombre; persona; individuo; libertad; moral; ética; razón; Ley moral; derecho de la persona. Todos estos conceptos están en relación con un módulo central donde se desarrolla el concepto de derechos humanos en el marco de la Línea de la Doctrina Social de la Iglesia. La misma tiene como eje la obra de Santo Tomás de Aquino.

Haciendo centro en la aparición de este modulo comencé a realizar una lectura transversal que pusiera en relación conceptos vertidos en el mismo. Es así que dentro del listado curricular revise las asignaturas cuyos contenidos aparecen, desde una primer lectura, relacionados con esta concepción de derechos humanos. Otro elemento importante es la

policial con el mapa judicial, creando 18 Jefaturas Departamentales; se abre una instancia de participación comunitaria donde gobiernos locales y organizaciones comunitarias pasan a formar parte de los foros de seguridad, con dos ejes principales: formulación de la política de seguridad a nivel local y control de la gestión policial. 
relación de estos contenidos con diferentes asignaturas tales como: Filosofía; Historia del pensamiento filosófico y político y ética profesional, entre otras.

- Este primer recorte es arbitrario en función de los propósitos de esta etapa de la investigación, y deja de lado los demás contenidos y aspectos formativos que ameritarían un estudio posterior. Mi interés en este primer recorrido es poner en foco ciertas continuidades en las prácticas y discursos presentes en el imaginario policial respecto de los derechos humanos.

A partir de 1972 el programa de estudio correspondiente al curso acelerado de 3 meses y al regular de 6 meses $^{15}$, se pudo relevar información mas completa. La misma consistió en un listado de materias con el índice de módulos y bibliografía correspondiente.

Un dato interesante que de alguna manera refleja la escasa importancia dada a la formación, es el estado y tipo de información. Todo el material esta desorganizado, sin clasificar, mezclado y recortado.

El listado de asignaturas correspondientes con dichos años los organice en un cuadro para poder realizar un análisis comparativo.

Los agrupé tomando como criterio los siguientes ejes y respetando el orden cronológico:

1. Relato histórico de la constitución del estado/nación presente en las asignaturas: Formación nacional; Historia de la instituciones Políticas y civiles; Historia de las instituciones políticas y sociales y formación nacional; Historia del pensamiento contemporáneo; Historia contemporánea y argentina; Historia social argentina.

2. Concepciones de filosofía, moral y ética de la práctica profesional presentes en las asignaturas: Filosofía y Ética policial; Educación moral y religiosa; Historia del pensamiento filosófico y político, y ética policial; Filosofía; Nociones de Filosofía y ética; Lógica , filosofía y formación ética ; Ética aplicada a la función.

3. Relación entre Derecho, DDHH y conducta policial, presente en las asignaturas: Instrucción Cívica y elementos de Derecho civil; Derecho Constitucional y DDHH; Derecho Constitucional; Derechos Humanos y Función Policial.

4. Construcción de la criminalidad/ construcción de la peligrosidad/ criminalización social: Inteligencia (1976 a 1985); Criminología; investigación criminal.

La asignatura Derecho Constitucional y Derechos Humanos aparece por primera vez en la curricula correspondiente al ciclo lectivo de 1987.

15 La diferencia de los cursos ( 3 y 6 meses) tiene que ver con el ingreso de cadetes que no tiene completo su nivel medio, y que con acuerdo del Ministerio de Cultura y Educación de Nación se completaba dentro de la Escuela de Cadetes Juan Vucetich, en el denominado Bachillerato Policial. 
A partir del año 2004 cambia el plan de estudios muy significativamente: desaparece las asignaturas cuyos contenidos hacían referencia a filosofía o ética $y$, la asignatura correspondiente con contenidos de derechos humanos pasa a denominarse Derechos Humanos y función policial.

\section{LA CONSTITUCION DE LA PASTORAL ${ }^{16}$ FUCOULTIANA:}

\section{La Doctrina Social de la Iglesia en la formación policial:}

- ¿ ¿porque esta presente en la formación policial la Doctrina Social de la iglesia?

- ¿que valores, conceptos, sentidos imprime/estructura en las practicas de los sujetos?

- ¿Que construcciones de la peligrosidad/amenazas están presentes?

En los años anteriores a 1987 no aparece ninguna asignatura específica sobre derechos humanos. Sin embargo realizando un repaso en los contenidos curriculares de diferentes asignaturas, se puede encontrar contenidos relacionados con DDHH desde la perspectiva de la Doctrina social de la Iglesia en un modulo que se repite al interior de diferentes asignaturas.

Dicho módulo tiene los siguientes contenidos:

"Santo Tomas de Aquino; León XIII: Rerum Novarum; Pío XII: inviolabilidad de los derechos esenciales del hombre; Juan XXIII: Encíclica Pacem in terris; Concilio vaticano II: Constitución Conciliar Gaudium et spes: El valor de la persona y sus derechos esenciales.

Juan pablo II: derechos humanos desde la concepción. Hombre y libertad: fundamentos filosóficos $^{17 .}$

Y se halla presente en las siguientes asignaturas: Formación nacional y filosofía (1972, 1976; Filosofía y ética policial (1978, 1984); Educación moral y religiosa (1984); Derecho constitucional y derechos humanos, Historia del pensamiento filosófico y político y ética policial, Instrucción cívica y elementos de derecho civil (1985); Derecho constitucional y derechos humanos (1987); Derecho constitucional y derechos humanos, historia del pensamiento contemporáneo (1989); Derecho constitucional y derechos humanos (1992).

Es importante registrar aquí la continuidad de dicha concepción desde 1972 hasta el año 1992.

\footnotetext{
${ }^{16}$ En su análisis del poder pastoral, Foucault encuentra que allí se manifiesta una preocupación que hace al núcleo de la razón de Estado moderna: la articulación entre una forma de poder totalizante e individualizante a la vez. De tal articulación se deriva el eje constitutivo de la noción de Gobierno, cuya finalidad se orienta a la conducción, dirección y previsibilidad de las conductas. Así, el poder pastoral estará directamente ligado tanto a ciertas técnicas de individualización como al gobierno del "rebaño" y a la salvación de este último.

Es a partir del análisis histórico de esta noción, de su estrecha vinculación con el desarrollo del cristianismo en Europa y de la influencia que tal modelo de conducción de hombres dejará como impronta en la razón de Estado moderna que Foucault propondrá una historia de la gubernamentalidad.

17 Copia textual del modulo correspondiente a las asignaturas en cuestión. Con algunas modificaciones, se mantiene a lo largo de todos estos años.
} 
Otros contenidos que están en estrecha relación con los DDHH desde dicha perspectiva, están entretejidos en las asignaturas mencionadas, de diferentes maneras. Por ejemplo en la asignatura Formación Nacional esta estrechamente unido al discurso de la Dictadura militar que aparece con toda su significación, constituyendo el sentido predominante en la formación profesional que aún sigue vigente en los subsuelos de la formación y las conductas de mucho de sus integrantes. Es por ello que me parece relevante realizar una lectura transversal de dichos contenidos. En los objetivos se menciona: "ubicar al alumno dentro de la perspectiva histórica y tradicional, para fortalecer sus sentimientos patrióticos y cristianos, subrayando o rectificando los contenidos espirituales y morales que conforman su personalidad"18 Los contenidos ${ }^{19}$ se presentan hilvanados a través de diferentes ejes, alrededor de dos fuentes de interpretación presentadas como: Filosofía aristoltélico-tomista vs. Interpretación filosófica materialista/marxista.

\begin{tabular}{|c|c|}
\hline Filosofía aristotélico-tomista & Filosofía materialista/ Marxista \\
\hline 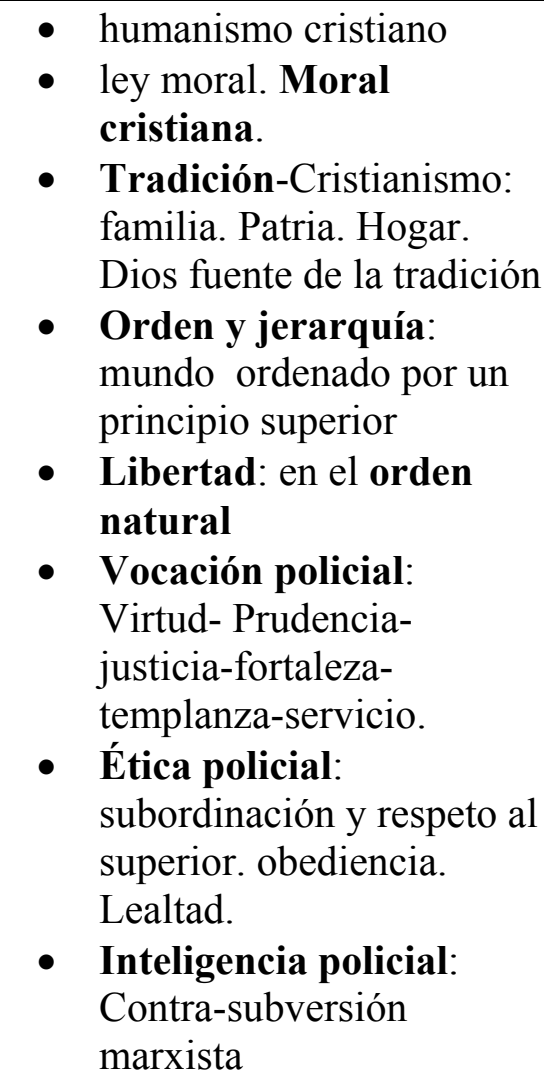 & $\begin{array}{l}\text { Humanismo ateo. } \\
\text { - Hombre sin ideales: deshumanización del } \\
\text { hombre. } \\
\text { - quebrantamiento del orden tradicional: } \\
\text { negación de los valores tradicionales. } \\
\text { anticristianismo- ocultamiento del nivel } \\
\text { metafísico del hombre-desconocimiento del } \\
\text { orden y la jerarquía. } \\
\text { - Liberalismo. Anarquismo. Socialismo } \\
\text { - sinarquía/populismo/subversión } \\
\text { - liberalismo }\end{array}$ \\
\hline
\end{tabular}

18 Objetivos enunciados en la asignatura Formación Nacional del programa correspondiente al año 1976.

${ }^{19}$ Ver anexo. Los conceptos presentes en el cuadro forman parte de los contenidos de diferentes asignaturas. 
Si nos detenemos en este par de oposiciones conceptuales que se pueden rastrear a través de todos los contenidos especificados en las asignaturas vemos como se va delineado un sentido que orienta la construcción de la peligrosidad vigente fuertemente en la última dictadura en la argentina. Gilberto Velho elabora el concepto de categoría acusatoria para analizar los prejuicios en Brasil en la misma época. El par de delincuente- subversivo unificó un solo sentido dominante en toda la región.

\section{DOCTRINA SOCIAL DE LA IGLESIA Vs. TEOLOGIA DE LA LIBERACIÓN}

Para comprender la presencia en los contenidos curriculares de dichos marcos interpretativos opuestos, realicé un repaso por las encíclicas mencionadas. La más significativa en tanto reúne los conceptos centrales de la denominada Doctrina social de la Iglesia, ${ }^{20}$ es la Carta

\section{Encíclica Rerum Novarum de León XIII.}

Escrita en 1891, gira alrededor de la relación entre capital y trabajo, desde tres ejes centrales: la naturaleza del hombre, el derecho a la propiedad y el peligro que representa las concepciones marxistas, que son presentadas como amenaza al hombre, a la propiedad privada y al Estado democrático.

En primer lugar presenta la relación entre trabajo y capital como una relación problemática. La tarea de la Iglesia en ese sentido, es presentada como un llamado a la reconciliación, a la armonía entre las clases: "asi ha dispuesto la naturaleza que, en la sociedad humana, dichas clases gemelas concuerden armónicamente y se ajusten para lograr el equilibrio. Ambas se necesitan en absoluto: ni el capital puede subsistir sin el trabajo, ni el trabajo sin el capital".

De este acuerdo entre las clases surge el orden como oposición a la "violencia y salvajismo de los sectores sediciosos". Este "orden" es necesario para el goce del derecho natural a la propiedad: “(...) Poseer bienes en privado, según hemos dicho poco antes, es derecho natural del hombre, y usar de este derecho, sobre todo en la sociedad de la vida, no sólo es lícito, sino incluso necesario (...)es un deber socorrer a los indigentes con lo que sobra”.

Este equilibrio entre clases necesita para realizarse de la caridad y de la naturalización de la pobreza por parte de los pobres: "Lo que sobra, dadlo de limosna (...) Los que, por el

20 En el documento Compendio de la Doctrina social de la Iglesia del Pontificio Consejo« Justicia y Paz » se define: "El cristiano sabe que puede encontrar en la doctrina social de la Iglesia los principios de reflexión, los criterios de juicio y las directrices de acción como base para promover un humanismo integral y solidario (...). para que las personas, iluminadas por ella, sean capaces de interpretar la realidad de hoy y de buscar caminos apropiados para la acción: Los aspectos teológicos, filosóficos, morales, culturales y pastorales más relevantes de esta enseñanza se presentan aquí orgánicamente en relación a las cuestiones sociales. " 
contrario, carezcan de bienes de fortuna, aprendan de la Iglesia que la pobreza no es considerada como una deshonra ante el juicio de Dios y que no han de avergonzarse por el hecho de ganarse el sustento con su trabajo".

En esta lógica, la perspectiva teórica y política de inspiración marxista es presentada como una amenaza, como el mal y la incitación a la violencia y al desorden: amenazas a la propiedad, al estado democrático, al orden establecido y fundamentalmente a la Iglesia.

Desde una postura opuesta ${ }^{21}$ encontramos el pensamiento y doctrina de la Teología de la Liberación surgidas durante ejercicio papal de Juan XXIII y Paulo VI, en el marco del Concilio Vaticano II. En el contexto socio histórico de guerra fría la Iglesia manifiesta su preocupación por la paz y el orden social, producto de la misma se halla expresada en cierta forma en la carta pastoral Pacem in terris (1963) ${ }^{22}$ es la ultima encíclica de Juan XXIII. Tiene como conceptos centrales el orden en el universo y en la humanidad. El orden que debe regir las relaciones entre los hombres y con el estado. Entre las personas humanas este orden se expresa en términos de derechos y deberes, y con el Estado democrático, como necesaria autoridad que garantice el bien común: "En efecto, como Dios ha creado a los hombres sociales por naturaleza y ninguna sociedad puede conservarse sin un jefe supremo que mueva a todos y a cada uno con un mismo impulso eficaz, encaminado al bien común, resulta necesaria en toda sociedad humana una autoridad que la dirija; autoridad que, como la misma sociedad, surge y deriva de la naturaleza, y, por tanto, del mismo Dios, que es su autor". 23

Con respecto al concepto de orden se sigue manteniendo el concepto desde la fillosofía aristotélico-tomista de orden, donde Dios es el principio ordenador por excelencia y el Estado su expresión.

La carta realiza un recorrido de $\operatorname{los}$ derechos ${ }^{24}$ y los deberes del hombre y establece una conexión "necesaria" entre los mismos: "Los derechos naturales que hasta aqui hemos recordado están unidos en el hombre que los posee con otros tantos deberes, y unos y otros tienen en la ley natural, que los confiere o los impone, su origen, mantenimiento y vigor indestructible. El deber de respetar los derechos ajenos".

\footnotetext{
${ }^{21}$ La oposición se encuentra expresada mas fuertemente en la práctica y concepciones de los sacerdotes tercermundistas, no tanto así en dichas encíclicas.

22Escrita por Juan XXIII en el año1963, es presentada como: "Sobre la paz entre todos los pueblos que ha de fundarse en la verdad, la justicia, el amor y la libertad."

${ }^{23}$ Juan XXIII, op. Cit.

24 "Derecho a la existencia y a un decoroso nivel de vida; Derecho a la buena fama, a la verdad y a la cultura, Derecho al culto divino, Derechos familiares, Derechos económicos, Derecho a la propiedad privada, Derecho de reunión y asociación, Derecho de residencia y emigración, Derecho a intervenir en la vida pública, Derecho a la seguridad jurídica"
} 
La Constitución Pastoral Gaudium et spes (1965), "sobre la iglesia en el mundo actual ofrece al género humano la sincera colaboración de la Iglesia para lograr la fraternidad universal". Realiza un diagnostico de la situación mundial y de las amenazas que penden sobre el. Retoma los conceptos de: dignidad de la conciencia moral; libertad; promoción del bien común y respeto por la persona humana. ${ }^{25}$

La Teología de la Liberación recoge la preocupación y compromiso de un sector de la iglesia con los más pobres. Surgida al interior de la iglesia católica, madura en el marco del Concilio Vaticano II y reconoce en términos generales a Juan XXIII como un referente. En sus palabras: "frente a los países subdesarrollados, la Iglesia se presenta tal como es y quiere ser: como la Iglesia de todos, particularmente, la Iglesia de los Pobres „26.

En Latinoamérica, el Concilio significó para los creyentes un profundo cambio, ya que permitió según este movimiento, el contacto de las órdenes religiosas con las necesidades sociales. En mucho casos, los integrantes del las Iglesias de cada país se identificaron con los movimientos de liberación. "La teología de la liberación" tomo forma luego de la Conferencia de Medellín de $1968^{27}$ del CELAM.

¿Por qué tanta preocupación por dar una discusión en torno a las posturas opuestas dentro de la iglesia, en la formación policial?

En un contexto donde las dictaduras gobernaban la región, la idea de "Iglesia de los pobres" fue interpretada por algunos sacerdotes con un claro compromiso político y social transformador. De esta forma, el compromiso social hizo que los sacerdotes llamados "tercermundistas", en los que predominaba una evangelización cargada de alto contenido social, se acercaran a los movimientos de liberación que utilizaban la lucha armada. Muchos sacerdotes, que abrazaron estas ideas, fueron perseguidos y asesinados por defender estas prédicas evangélicas y llevarlas a la práctica. Como era de esperar, a Roma y a los regímenes conservadores no les gustó la matriz marxista de la “teología de la liberación".

Durante las dictaduras militares en América Latina en general, se llevó a cabo una violenta represión del movimiento. Los asesinatos cometidos por escuadrones de la muerte, los encarcelamientos y torturas, se incrementaron. El arzobispo de El Salvador, Oscar Romero, el

\footnotetext{
25 Ítems destacados en la encíclica.

${ }^{26}$ Mensaje de Juan XXVIII, en 1962

${ }^{27}$ La Conferencia de Medellín, donde se reunió el Consejo Episcopal Latinoamericano (CELAM), en 1968, se inspiró en las reformas del concilio Vaticano II. En la misma, los obispos publicaron un documento en el que examinaban el papel social de la Iglesia en sus respectivos países. Allí, denunciaban la opresión del sistema capitalista sobre los pobres, criticaban la explotación que ejercían los países centrales por sobre los del "tercer mundo" y exigían numerosas reformas políticas y sociales.
} 
padre Antonio Pereira Neto, de Brasil, y el obispo de La Rioja, monseñor Enrique Angelelli, se convirtieron en mártires del movimiento.

\section{LA DOCTRINA SOCIAL DE LA IGLESIA Y LOS DERECHOS HUMANOS}

De una lectura transversal de la Doctrina Social de la iglesia, a través de sus pilares fundamentales cuales son las encíclicas y discursos papales, se puede organizar una lectura centrada en los conceptos organizadores de una hermenéutica iusnaturalista sobre los derechos humanos, concebidos como derechos naturales de la persona humana. $\mathrm{Y}$ es justamente Tomás de Aquino filósofo y teólogo del siglo XIII, uno de los más importantes representantes de dicha concepción dentro de la doctrina teológica católica.

Los conceptos centrales que sirven de fundamento son:

- $\quad$ Ley natural; derecho natural=derecho de la persona humana

- $\quad$ Naturaleza humana

- Bien común; derechos y deberes: estado democrático y autoridad/orden.

- La centralidad del derecho a la vida, a la propiedad y a la religiosidad como uno de los principales derechos humanos.

- $\quad$ Orden y jerarquía. Mundo ordenado por un principio superior: Dios

EL PENSAMIENTO DE TOMAS DE AQUINO COMO FUNDAMENTOS DE LOS DERECHOS DE LA PERSONA HUMANA

Para J. G. López las consideraciones que fundamentan los derechos humanos concebidos como derechos de la persona humana en Tomás de Aquino, remiten a considerar la coincidencia de los derechos naturales con los derechos humanos. Se trata de derechos primarios o fundamentales, que resultan de las inclinaciones naturales en el hombre y no, de derechos secundarios, o positivos.

Se parte en primera instancia desde esta perspectiva, de una identificación de derechos naturales/derechos humanos. Se refiere a los derechos que corresponden al hombre como ser racional, libre y social por naturaleza. La libertad es concebida como capacidad de elegir por deliberación.

“los derechos humanos serán por una parte los que riman con la razón humana, y no con la pura inteligencia, como tampoco con la sensibilidad, y por otra, los que nacen de la voluntad 
libre... los contenidos en los dictámenes inferidos por le ejercicio de la razón practica a partir de la misma ley natural" 28

En la libertad y la sociabilidad, como propiedades derivadas de su racionalidad, descansan los derechos humanos. Para el autor estos derechos fueron estudiados por T. de Aquino como "derecho de gentes":

"el derecho de gentes es de algún modo natural al hombre en tanto que es racional, pues se deriva de la ley natural (...)”.29

En este sentido los derechos humanos prolongan los derechos naturales. Se conciben como derechos/ libertades.

Como resumen el autor plantea primero, que los derechos puramente naturales tienen que ser filtrados en el hombre por su racionalidad. El derecho a la vida no se trata del mero vivir, sino de vivir de una manera digna, todo lo cual conlleva otros derechos, entre ellos el derecho a la propiedad. Segundo, que los derechos humanos contienen principios relativos a la convivencia social y al ejercicio de la libertad política y ciudadana y tienen como meta el bien común. La ley es una ordenación de la razón en pos del bien común. Y por último reconoce el derecho a la religión con lo cual el bien común se ordena según la trascendencia divina de $\operatorname{Dios}^{30}$

Otro de los conceptos centrales para entender la relación Jesús García López se refiriéndose al concepto de propiedad privada como un derecho natural en Tomás de Aquino: "la posesión y dominio de las cosas exteriores es natural al hombre, pues lo imperfecto está subordinado lo perfecto y, por consiguiente, las cosas están subordinadas a las personas. Pero aquí no se trata todavía de la propiedad privado de la distribución asignación de las cosas exteriores a determinadas personas; es un derecho que todas las personas tienen a todas las cosas, como viene necesario para su subsistencia y desarrollo". ${ }^{31 .}$

Desde este concepto de naturaleza del hombre se sigue el fundamento natural de la propiedad privada. Lo que se deriva en relaciona con el anterior es la naturalización de las desigualdades: " $Y$ hay por naturaleza entre los hombres muchas y grandes diferencias; no son iguales los talentos de todos, ni la habilidad, ni la salud, ni lo son las fuerzas; y de la inevitable diferencia de estas cosas brota espontáneamente la diferencia de fortuna. Todo esto en correlación perfecta con los usos y necesidades tanto de los particulares cuanto de la

28 Jesús García López, Los derechos humanos en santo Tomas de Aquino, pag. 26

29 Aquino, Tomas, Suma Teológica, Parte I,II, Cuestión 95.

30 Jesús García López, op. Cit.

31 Jesús García López, Los derechos humanos en Santo Tomas de Aquino, Ediciones Universidad de Navarra, S. A., Pamplona, 1979, Pág. 113. 
comunidad, pues que la vida en común precisa de aptitudes varias, de oficios diversos, al desempeño de los cuales se sienten impelidos los hombres". 32

Otro de los conceptos centrales es el bien común, donde claramente se pone de manifiesto la relación entre la religiosidad y los "asuntos humanos": el estado/iglesia católica. En esta relación hay un claro reconocimiento y legitimación mutua de dos autoridades:

"el Espíritu Santo impulsa precisamente a las personas espirituales a someterse a las leyes humanas. Acatad toda institución humana por amor de Dios. (...) Hay que advertir, sin embargo, que, si la observancia literal de la ley no da pie a un peligro inmediato al que se haya de hacer frente sin demora, no compete a cualquiera interpretar qué es lo útil o lo perjudicial para el Estado, sino que esto corresponde exclusivamente a los gobernantes, que, con vistas a estos casos, tienen autoridad para dispensar de las leyes (...) La ley humana para ser correcta debe estar en consonancia con las leyes natural y divina, pues, de lo contrario, no estaría en armonía con la religión, ni sería conveniente para la disciplina”. ${ }^{33}$

\section{LOS FUNDAMENTOS EN LA DOCTRINA SOCIAL DE LA IGLESIA EN LA ACTUALIDAD}

En un rápido repaso por los teóricos actuales que plantea los fundamentos de los derechos humanos desde la Doctrina social de la Iglesia, encontramos al cardenal, arzobispo de Madrid Antonio María Rouco Varela ${ }^{34}$ como uno de los mas importantes.

En un artículo presentado en ocasión del ingreso a la Real Academia de Ciencias Morales y Políticas- España en el año 2004, plantea la utilidad de la fundamentación de los derechos humanos, dado el escepticismo posmoderno con respecto a lo que ocurre "con el hombre y sus derechos más elementales".

Con respecto a las violaciones de los derechos humanos plantea dos consideraciones con respecto a la plena vigencia de los Derechos Humanos en los viejos y nuevos estados.

Uno de los factores, según el autor, que pone freno a la plena realización de los derechos humanos es la influencia de una concepción marxista leninista: "la influencia de una

32 Tomas de Aquino: Suma Teológica. Primera sección de la Segunda parte.

33 Ídem, Suma teológica, Primera sección de la Segunda parte.

$34 \mathrm{Ha}$ publicado sobre derechos fundamentales y libertad en la sociedad y la Iglesia católica, en obras como: Un pensamiento al servicio de la "persona humana", artículo para el libro-homenaje a D. Julián Marías, publicado por FUNDES. Madrid, 27 de mayo de 2002; Fundamentos eclesiológicos de una teoría general de los derechos fundamentales del cristiano en la Iglesia, en "Les Droits Fondamentaux dans l'Eglise et dans la Société. Actes du IVe Congres International de Droit Canonique", Fribourg-Suisse 1981, 53-78; Los Fundamentos de los Derechos Humanos: una cuestión urgente. Madrid, San Pablo, 2001; Democracia o libertad en la Iglesia, Cuenta y Razón 90-91-92 (1995) 31-38. 
concepción revolucionaria, de inspiración marxista-leninista, y aún estalinista de los derechos humanos, que los menospreciaba como prejuicios burgueses, actuó sin duda como un factor claramente perturbador y como freno, en muchos de los países del llamado tercer mundo".

Otra de las consideraciones o factores que toma es el peso de las propias tradiciones culturales y religiosas de algunos estados de Europa central y oriental que han salido del sistema comunista. Las mismas según el autor, inclinan la balanza a una dirección distanciada de la doctrina y la praxis de las Naciones Unidas. Da el ejemplo de la organización de la Conferencia Islámica en el año 1990 en El Cairo donde se redacta la Declaración de los derechos humanos en el Islam, y que establece la Shari'a como criterio hermenéutico de interpretación. Aquí pone un punto de peligro o alerta con respecto a posturas relativistas: "el peligro de que este relativismo culturalista termine por convertirse en un relativismo teórico práctico y ciencias humanas más fundamentales salta a la vista en los usos políticos y jurídicos de no pocos estados actuales".

La doctrina del derecho natural para este autor es un instrumento valioso centrado en la renovación moral y espiritual de las sociedades convulsionadas por la guerra y, un instrumento para la reconstrucción democrática del estado basada en el reconocimiento y garantía de los derechos humanos. En tal sentido el arzobispo habla del éxito filosófico teológico del derecho natural en la reconstrucción de los países europeos después de la segunda guerra.

El autor caracteriza como "Liberacionismo", diferentes movimientos políticos surgidos en el marco de la descolonización en los países del tercer mundo, dentro de los cuales podemos inscribir la "Teología de la liberación"35 : " la fascinación que ejerce el socialismo marxista y sus supuestos proyectos liberadores (...) una crisis galopante de fe y de la moral personal y familiar(...) se conjuraron como otros factores históricos en la generación de un singular fenómeno histórico cultural que bien podría definirse como liberacionismo".

Caracteriza como fundamentos de este liberacionismo a la escuela de Frankfurt e identifica como sus principales integrantes a M. Horkheimer, Th. W. Adorno, Habermas, Marcuse, Gramsci y "un Sartre tardío”.

35 La Teología de la Liberación es un movimiento surgido al interior de la iglesia católica que madura en el marco del Concilio Vaticano II y reconoce a Juan XXIII como un referente. En sus palabras: "frente a los países subdesarrollados, la Iglesia se presenta tal como es y quiere ser: como la Iglesia de todos, particularmente, la Iglesia de los Pobres". El Concilio mostró un alto interés en cambiar algunos aspectos importantes dentro de la iglesia. Además de sentar las bases para una mayor participación de la Iglesia en los problemas del mundo, fue la presencia de obispos de todo el mundo, sobre todo, de obispos del llamado "tercer mundo" los que produjeron cambios significativos en la doctrina de la Iglesia Católica. En mucho casos, los integrantes del las Iglesias de cada país se identificaron con los movimientos de liberación. 
Hace una crítica a la teología de la liberación y a su metodología marxista para el análisis de la realidad social y la considera atentatoria contra la doctrina social de la Iglesia. Un cuestionamiento radical al derecho natural sustentado por ella. Relaciona a la teoría a la teología de la liberación con el liberalismo relativista de entre-guerra disfrazado de progresismo liberal. "Éste postulado de las doctrinas liberacionistas, de conseguir la igualdad de los hombres por medio de la emancipación de las instituciones incluidas las instituciones propias del estado democrático, abriendo el juego a nuevos totalitarismos”.

A todo esto le opone la filosofía y doctrina social de la Iglesia y sus definiciones de dignidad humana presentes en las enseñanzas de los papas, y sus encíclicas.

superioridad del modelo democrático de estado, y surge una nueva versión del liberalismo enraizado en la teoría y práctica de la economía de mercado en donde la cuestión de los derechos humanos sufre una irremediable pragmatización.

El arzobispo hace especial hincapié en la encíclica de León XIII Rerum novarum en tanto contiene un diagnóstico cultural y espiritual y reclama la recuperación de un humanismo trascendente.

Y agrega más adelante una serie de interrogantes, que me parece son sumamente importantes pues es donde se pone en evidencia su perspectiva iusnaturalista: ¿Cómo se conoce y prueba que existen derechos que son inherentes a la persona humana, anteriores y superiores a cualquier ordenación positiva jurídica (...) ¿cual es la fuente y origen de su legitimidad y autoridad?

Su respuesta esta centrada en una "antropología metafísica": "que conoce al hombre como ser racional y libre, auto conciente, autónomo, dueño de si mismo, en comunicación con otros hombres (...) si se reconoce que el hombre es persona, entonces habremos dado un paso definitivo en la fundamentación de los derechos humanos".

Su definición de hombre esta inexorablemente ligada a las otras "inherencias/ naturalizadas": "bienes y valores como la vida, la verdad, la libertad, asignación de bienes materiales: la propiedad privada, el matrimonio, la participación social y política, la religiosidad”.

De todas estas consideraciones podemos concluir en primera instancia que los ejes planteados por dicha doctrina en lo referente a los derechos humanos, postula muy fuertemente un agguiornamiento de los postulados de la Rerum Novarum:

- una vuelta a las fuentes del derecho natural por un lado

- y una reafirmación de las viejas amenazas socialistas, marxistas que de la mano del "liberacionismo" de adentro: Teología de la liberación; y de afuera: las corrientes teóricas fundadas por la Escuela de Frankfurt, luchan contra el Derecho Natural y 
ponen en crisis a los derechos humanos en tanto niegan "la verdad de la persona humana" y sus "inherencias/ naturalizadas".

- Otro peligro señalado son las posturas relativistas que se oponen al fundamento iusnaturalista universalizante y que conforman una "alianza entre democracia y relativismo ético".

\section{CONCLUSIONES PRELIMINARES}

De este recorrido por la Doctrina social de la Iglesia como uno de los marcos teóricos centrales en la formación policial en la última dictadura, podemos ver su impronta en términos de marcos interpretativos propuestos para la función policial y fundamentalmente el lugar central que ocupa en ellos los fundamentos de derechos humanos. Podríamos considerarla como una renovada forma de poder pastoral. El establecimiento de las técnicas pastorales en el cuadro del aparato estatal es para Foucault la matriz de la razón política moderna que transforma los individuos en sujetos y los inserta en unas estrategias globales de gestión de las poblaciones. Es en este proceso de constitución del estado moderno que denomina gubernamentalidad donde la pastoral cristiana y estado de policía se encabalgan y se prolongan hasta las sociedades contemporáneas a través del bio-poder, articulando técnicas específicas de saber, control y coerción. Las relaciones de poder son entonces definidas históricamente por cierta racionalidad. Aquello que Foucault denominará "el arte de gobernar" comprende tres elementos: la transferencia de las voluntades individuales a un poder soberano, la relevancia del aparato estatal y de un conjunto de técnicas para conducir (dirigir) a los hombres, técnicas de producción de comportamientos corporales (las disciplinas), pero también técnicas para conducir las almas (pastoral cristiana).

Es en sentido que se puede interpretar ese gobierno de las almas y los cuerpos a través de las disciplinas que operan al interior de la formación policial, en el andamiaje complejo que recorre todos los laberintos de la institución, desde la escuela, la calle, las comisarías, en el despliegue las "intervenciones policiales".

La formación policial tiene un eje estructurante: moral- obediencia- orden- servicio, son los componentes alrededor de los cuales adquiere sentido la función policial.

Finalmente esta forma de poder no puede ser ejercida sin el conocimiento de las mentes humanas, sin explorar sus "almas", sin hacerles revelar sus más íntimos secretos. Esto implica un conocimiento de la conciencia y la habilidad para dirigirla. 
¿Qué papel juegas dichas concepciones en la construcción secundaria de la peligrosidad ${ }^{36}$ que realiza la policía?

Una de las respuestas la tenemos con M. Saín : "Las personas sujetas a la criminalización secundaria son altamente vulnerables y sujetas a estigmatización criminalizante de dichas agencias (...) la criminalización secundaria es un pretexto para que las agencias policiales ejerzan un formidable control configurador positivo de la vida social que en ningún momento pasa por las agencias judiciales o las jurídicas(...).pero que constituyen un conjunto de atribuciones que pueden ejercerse de modo tan arbitrario como desregulado, y que proporcionan un poder muchísimo mayor y enormemente mas significativo que el de la reducida criminalización primaria. Sin duda que este poder configurador positivo es el verdadero poder político del sistema penal (...)El poder discrecional de las instituciones policiales es amplio y esta determinado por un selector cuyos factores constitutivos del conjunto de prácticas y marcas de referencias simbólicas que se reproducen históricamente en el interior de dichas instituciones y que tienen como itinerario estructurante esa selectividad",37.

Y por ultimo quisiera hacer una reflexión final. Pese a que resta revisar y clasificar gran parte del material perteneciente a la biblioteca de la Escuela Vucetich la de la Altos Estudios Policiales (CAEP), quisiera hacer mención a algunos materiales de reciente hallazgo para mí. Uno fue el Manual de Conducción policial, el manual de la discordia. Impreso en 1997, sin embargo circulaba como apuntes dentro de la escuela en años anteriores, y se habría usado hasta el año 2001. Y otro es la Síntesis histórica de la Policía de la Provincia de Buenos Aires $(1580$ - 1980) redactada en 1980 por el sucesor de Camps, el General Ovidio Riccheri.

Estos materiales forman parte de los contenidos vigentes en los subsuelos/comisarías de la formación policial, donde en palabras de muchos entrevistados, jóvenes egresados de la Tecnicatura en Seguridad Ciudadana (2004): “cuando llegas acá olvidate de lo que aprendiste en la escuela (Vucetich), aprendes con nosotros". La idea de la Santa Hermandad reconocida por Riccheri, como antecedentes de la historia de conformación de la policía de la provincia de Buenos Aires, nos da una idea de ese subsuelo donde se asientan estas nuevas formas de hermandad.

\footnotetext{
${ }^{36}$ Este concepto de construcción secundaria de la peligrosidad es utilizado por Marcelo Saín en su libro El Leviatán azul. Hace una diferencia entre criminalización primaria y secundaria: la secundaria es la acción punitiva ejercida sobre las personas concretas por la policía. La primaria es a través de la elaboración y sanción de la ley penal.

${ }^{37}$ Saín, M.: op cit Pág. 11
} 